\title{
A Study on Classification of Guangxi Multimodal Transport Hub Based on Cluster Analysis
}

\author{
Zhigao Liao ${ }^{\mathrm{a}^{*}}$ and Zuquan Zhou ${ }^{\mathrm{b}}$
}

\author{
School of management Guangxi University of Science and Technology, Liuzhou 545006, China \\ aLiaozhigao@126.com, b939569811@qq.com
}

Keywords: Multimodal transport hub; System clustering; Guangxi; Classification

\begin{abstract}
The Belt and Road" and ASEAN International Channel Strategy of Guangxi logistics transportation network layout and logistics infrastructure has put forward higher requirements, the construction of logistics transportation network in Guangxi is not perfect, logistics and transport dispersed, inefficient and other issues, for the classification of Guangxi multimodal transport hub will be able to realize the network and the integration, to improve the overall efficiency of Guangxi logistics transportation network, improve the comprehensive transportation efficiency. The selection of Guangxi 14 city multimodal transport nodes, constructing the evaluation index system of classification, and combined with the GDP, the total investment in fixed assets, the total industrial output value, whole sale and retail sales, highway Mileage and the amount of cargo and other six factors using Ward's clustering algorithm of multimodal transport hub city classification, to determine the level of the hub of the city, and the multimodal transport hub city division for comprehensive multimodal hub, regional multimodal hub, professional multimodal transport hub city.
\end{abstract}

\section{Introduction}

With the construction of "The Belt and Road" strategy and the international big channel facing ASEAN, Guangxi intermodal construction has a very good opportunity for development in these strategies. Multimodal transport (also known as combined transport) is the transportation of goods under a single contract, but performed with at least two different means of transport (by rail, sea and road, for example).

Multimodal transport can achieve the effective connection of the various transport modes, such as road transport, rail transport, water transport, air transport and so on. With its flexible, effective, high speed, simple and comprehensive, it has an irreplaceable advantage, and gradually occupy the dominant position in the transport system. With the development of logistics industry, as an important transportation infrastructure, the construction and healthy development of the intermodal freight hub will be better to promote the development of logistics and transport, and the overall quality of the comprehensive logistics and transportation services.

Reasonable division and location of the multimodal transport hub in Guangxi can not only speed up the distribution of goods, but also help to achieve economies scale, reduce logistics costs, and effectively promote the development of regional economy.

In foreign countries, the research of multimodal transport hub mainly focuses on the location and layout of multimodal transport hub nodes, so as to construct a reasonable logistics transportation network. Domestic research is mainly aimed at the eastern and central economic developed areas, with less research for the construction of the Guangxi multimodal transport network hub. This paper attempts to study the classification of the multimodal transport hub in Guangxi, and provide reference for the construction and layout of Guangxi multimodal transport hub network.

\section{Influence Factors Analysis of Hub Level}

In the classification of the urban level of the multimodal transport network, the specific circumstances of the 14 cities in Guangxi should be considered comprehensively, and then determine the key factors 
of the index.

Table 1 summarizes the influencing factors of the relevant literature, and provides reference for the division of Guangxi multimodal transport hub.

Table 1 references and influencing factors

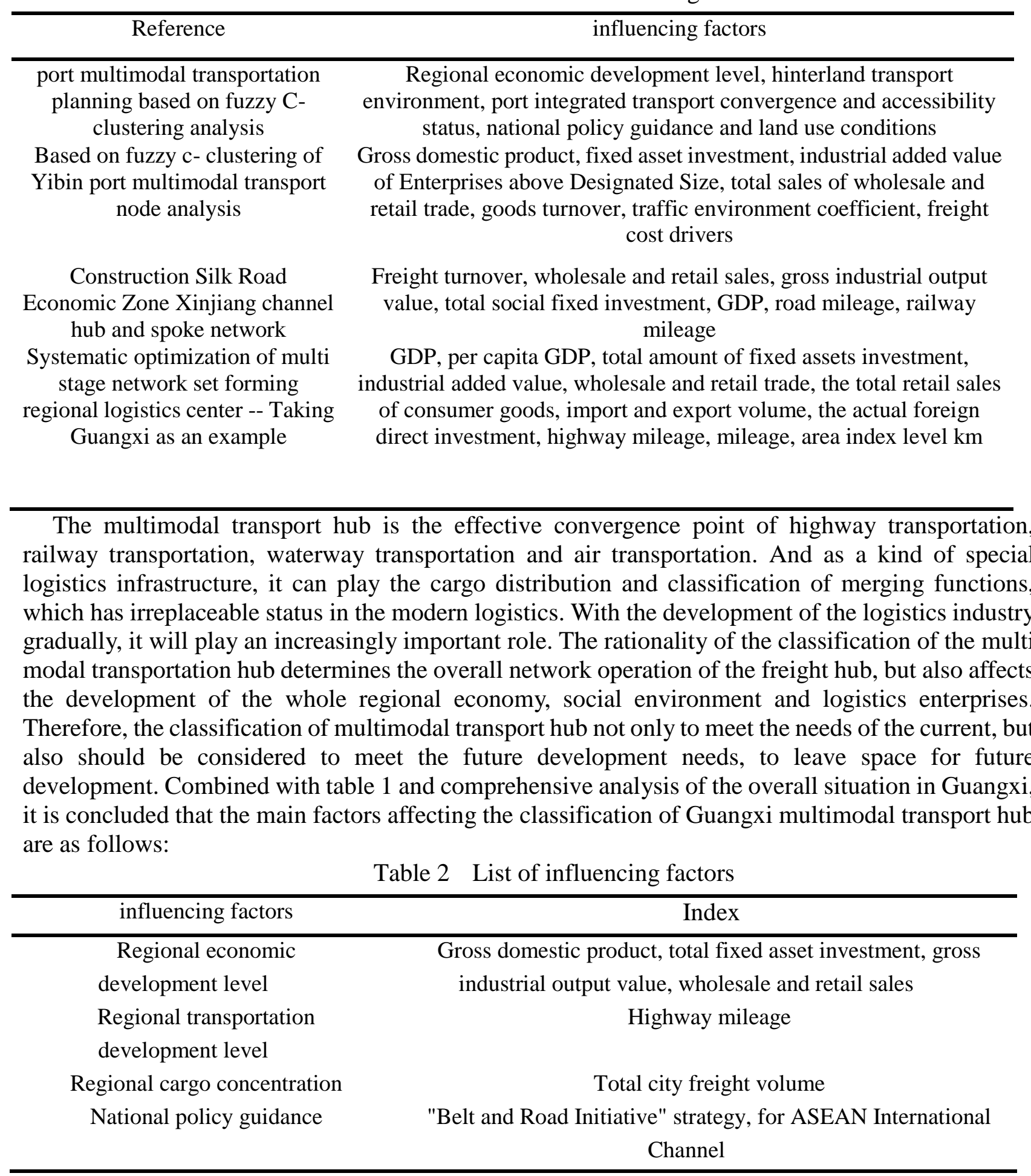

\section{Model Construction and Analysis of the Multi Modal Transportation Hub}

Index Selection. In this paper, the cluster Ward method is used to analyze of 14 multimodal transport hub cities in Guangxi and then determine the hub level of each city in Guangxi. Selection of GDP (100 million yuan), fixed asset investment (100 million yuan), the total industrial output value (100 
million yuan), wholesale and retail sales of goods (100 million yuan), the mileage of highways (km), freight volume (million tons) as key indexes, respectively marked as $X_{1}, X_{2}, X_{3}, X_{4}, X_{5}$ and $X_{6}$.

The first five data are from the Guangxi statistical yearbook 2014; the sixth data is from the "China City Statistical Yearbook 2014". The specific urban data of indicators can be seen in table 3.

Table 3 Index data of 14 cities in Guangxi

\begin{tabular}{|c|c|c|c|c|c|c|}
\hline City & $X_{1}$ & $X_{2}$ & $X_{3}$ & $X_{4}$ & $X_{5}$ & $X_{6}$ \\
\hline Nanning & 2803.54 & 2432.69 & 2557.13 & 2410.22 & 12195 & 32358 \\
\hline Liuzhou & 2010.05 & 1522.12 & 3917.85 & 964.33 & 8085 & 13783 \\
\hline Guilin & 1657.90 & 1308.46 & 1917.11 & 913.24 & 11784 & 8600 \\
\hline Wuzhou & 991.71 & 803.40 & 1733.17 & 95.77 & 5841 & 5599 \\
\hline Beihai & 735.00 & 674.90 & 1284.91 & 90.89 & 2586 & 6698 \\
\hline Fangchenggang & 525.15 & 455.81 & 964.41 & 90.06 & 2845 & 8123 \\
\hline Qinzhou & 753.14 & 559.03 & 1130.58 & 251.84 & 6170 & 27803 \\
\hline Guigang & 742.01 & 463.44 & 737.59 & 111.54 & 6621 & 11878 \\
\hline Yulin & 1198.46 & 953.59 & 1233.70 & 270.50 & 9747 & 19920 \\
\hline Baise & 803.58 & 802.50 & 974.45 & 308.08 & 15297 & 9261 \\
\hline Hezhou & 423.85 & 451.84 & 363.68 & 71.09 & 4439 & 4084 \\
\hline Hechi & 528.62 & 296.88 & 345.78 & 98.77 & 12331 & 6191 \\
\hline Laibin & 515.57 & 410.42 & 502.90 & 59.45 & 6194 & 2372 \\
\hline congzhou & 584.63 & 450.84 & 525.08 & 72.95 & 6935 & 4143 \\
\hline
\end{tabular}

Cluster Analysis. Cluster analysis by using the ward method in the system clustering method. Analysis process is the use of SPSS statistical analysis software for, analysis of clustering table. We use SPSS statistical analysis software for cluster analysis on the data of 14 multimodal transport nodes in Guangxi, the specific analysis results see Table 4.

Based on the results of cluster analysis, the 14 cities in Guangxi Can be clustered into three categories:

The clustering of situation can be adjusted as follows:

A comprehensive hub of multimodal transport: Nanning, Qinzhou;

Regional multimodal transport hub: Liuzhou, Guigang, Yulin city, Guilin, Heichi, Baise;

Professional multimodal transport hub: Hezhou, Wuzhou, Congzuo city, Laibin city.

Policy Analysis. The above classification of multimodal transport hub is considered the influence factors such as regional economic development level, regional transportation development level and regional centralization degree of goods, through the quantitative index and uses the method of system clustering-ward to determine the level of each hub city.

The strategy "B\&R" and the association of south-east Asian nations for international channel provide a better advantage and opportunities to Guangxi's multimodal transport development. However, the construction of the multimodal transport hub cities and regional logistics network is a long-term continuous process; the future development of a city must be considered. So it is necessary 
to adjust the hub level of some cities.

Table 4 The result of cluster analysis

\begin{tabular}{|c|c|c|c|c|c|c|}
\hline \multirow[b]{2}{*}{ Rank } & \multicolumn{2}{|c|}{ Cluster combination } & \multirow[b]{2}{*}{ coefficient } & \multicolumn{2}{|c|}{ First order cluster } & \multirow[b]{2}{*}{ Next rank } \\
\hline & Cluster 1 & Cluster 2 & & Cluster 1 & Cluster 2 & \\
\hline 1 & 5 & 6 & 1146232.195 & 0 & 0 & 8 \\
\hline 2 & 13 & 14 & 2992531.826 & 0 & 0 & 4 \\
\hline 3 & 4 & 11 & 6284032.014 & 0 & 0 & 4 \\
\hline 4 & 4 & 13 & 11171873.948 & 3 & 2 & 8 \\
\hline 5 & 3 & 12 & 16938622.331 & 0 & 0 & 6 \\
\hline 6 & 3 & 10 & 26353413.509 & 5 & 0 & 11 \\
\hline 7 & 2 & 8 & 36024590.627 & 0 & 0 & 10 \\
\hline 8 & 4 & 5 & 64364644.385 & 4 & 1 & 12 \\
\hline 9 & 1 & 7 & $1.001 \mathrm{E} 8$ & 0 & 0 & 13 \\
\hline 10 & 2 & 9 & $1.383 \mathrm{E} 8$ & 7 & 0 & 11 \\
\hline 11 & 2 & 3 & $2.542 \mathrm{E} 8$ & 10 & 6 & 12 \\
\hline 12 & 2 & 4 & $4.835 \mathrm{E} 8$ & 11 & 8 & 13 \\
\hline 13 & 1 & 2 & 1.299E9 & 9 & 12 & 0 \\
\hline
\end{tabular}

As the strategy of "B\&R" and the international thoroughfare facing the association of south-east Asian nations launching, the Beibu gulf ushers in the new development opportunities and has good prospects for development.

The Beihai was the starting point of the "Marine silk road", is also currently the only city in Guangxi have airport, harbor city, highway and railway.

Fangcheng port as one of the core cities of Guangxi Beibu gulf economic zone, national key layout of the steel energy base, the part of the Dongxin national key development experimental zone, and the part of Yunnan-Guangxi financial comprehensive reform pilot area, has special important strategic position in China-asean free trade area, so we divide Beihai and Fangcheng port into regional multimodal transport hub.

The city of Hechi is belongs to the resources industry city, and its key industries are non-ferrous metals, silkworm silk, energy and agricultural products. Its logistics infrastructure construction is very backward, and most of the logistics enterprise on a smaller scale, low competitiveness, backward logistics technology and equipment.

Baise mainly depends on the aluminum industrial base, subtropical characteristic agriculture base to construct the logistics park. However, the basement of logistics market has not yet fully established, all kinds of wholesale market's influence is not enough with small scale, and the logistics market main body of the infrastructure is not congruent.

So adjust the cities of Hechi and Baise for professional multimodal transport hubs.

The clustering of 14 cities in guangxi situation can be adjusted as follows:

A comprehensive hub of multimodal transport: Nanning, Qinzhou

Regional multimodal transport hub,Liuzhou, Guigang city, Yulin city, Guilin, Fangcheng gulf, Beihai

Professional multimodal transport hub: Hezhou, Wuzhou, Congzuo city, Laibin city, Hechi city and Baise. 


\section{Conclusion}

In order to strengthen the building international thoroughfare to the association of south-east Asian nations, make open development important area in central south regions in southwest, we research on the Multimodal transport network of Guangxi to support the its Strategic position as a important portal of organic link to maritime silk road and the silk road in the 21 st century economy.

In this paper, the authors put forward the concept of classification of multimodal transport hub in Guangxi, analyze the influence factors of multimodal transport hub in Guangxi and establish the index system, use the method of system clustering-ward to divide the 14 cities in Guangxi multimodal transport hub into three classes: comprehensive hub of multimodal transport, regional multimodal transport hub, professional multimodal transport hub.

(1) The classification of the multimodal transport hub in Guangxi can scientific position the transportation status of the cities in Guangxi, is conducive to complementary functions between regional transportation, and speed up the economic development in Guangxi.

(2) Through the classification of multimodal transport hub in Guangxi, can support the establishment of Guangxi traffic network construction, provide guidance basis for the strategic investment, infrastructure construction and traffic facilities layout of these cities.

\section{Acknowledgements}

Guangxi Philosophy and Social Science Fund (The Grant No. 13BGL009)

\section{References}

[1] Yang Youhui. Study on the location of the multimodal transport hub [D]. Chang'an University, 2011

[2] Goldman, A.J. Optimal location for centers in a network [J]. Transportation Science 3, 352-360, 1969

[3] O'Kelly, M.E. A quadratic integer program for the location of interacting hub facilities [J]. European Journal of Operational Research 32 (3), 393-404, 1987

[4] Slack, B. Intermodal transportation in North America and the development of inland load centers [J]. Professional Geographer 42 (1), 72-83, 1990

[5] O’Kelly, M.E., Lao, Y. Mode choice in a hub-and-spoke network: A zero-one linear [J].1991

[6] Limbourg, S., Jourquin, B. Optimal rail-road container terminal locations on the European network[J]. Transportation Research (E) 45 (4), 551-563, 2009

[7] Huang Tianqi, Huang Li, Dou Yu. Based on fuzzy c- clustering of Yibin port multimodal transport node analysis [J]. Logistics technology, 2014, 19:220-222.

[8] Wang Peipei, Wang Zhe, Huang Fojun, Dai Yan. [J]. economic geography construction Silk Road Economic Zone Xinjiang channel hub and spoke network, 2016,02:125-130.

[9] Qin Li Gong, Wang Mingxian. Systematic optimization of multi stage network set forming regional logistics center -- Taking Guangxi as an example [J]. Innovation, 2008, 1105:48-51. 